\title{
APPLICATION OF POWDERY ACTIVATED CARBONS FOR REMOVAL IBUPROFEN FROM WATER
}

\author{
Alicja Puszkarewicz' ${ }^{1}$ Jadwiga Kaleta', Dorota Papciak' \\ 1 Rzeszow University of Technology, The Faculty of Civil and Environmental Engineering and Architecture, Dept. \\ of Water Purification and Protection, Poznańska St. 2, 35-084 Rzeszów, Poland, e-mail: apuszkar@prz.edu.pl
}

Received: 2017.05.04

Accepted: 2017.06.01

Published: 2017.07.01

\begin{abstract}
The paper presents the results of studies on the use of adsorptive properties of selected powdered activated carbons (Norit SA Super and Carbopol MB5) for removal of ibuprofen from water. The tests were performed on non-flow conditions, series depending on the type and dose of powdered adsorbents. The research was carried out on a model solution of ibuprofen at initial concentration $\mathrm{C}_{0}=20 \mathrm{mg} / \mathrm{dm}^{3}$, at $20{ }^{\circ} \mathrm{C}$. Froundlich and Langmuir adsorption isotherms were used. Lagergrene kinetic models (PFO) and Ho (PSO) were used to describe adsorption kinetics. Both carbons exhibited a higher affinity for the adsorbent at $\mathrm{pH}$ above 7. Norit SA Super was a better adsorbent, for which, the highest adsorption capacity $\mathrm{q}=0.448 \mathrm{~g} / \mathrm{g}$ was achieved with dose D $=35 \mathrm{mg} / \mathrm{dm}^{3}$. The effectiveness of adsorption (decrease of ibuprofen in water) was $78 \%$. The total removal of ibuprofen was obtained for a dose of carbon D $=200 \mathrm{mg}$ / $\mathrm{dm}^{3}$. With respect to Carbopol, the highest adsorption capacity $(\mathrm{q}=0.353 \mathrm{~g} / \mathrm{g})$ was achieved at a dose of $30 \mathrm{mg} / \mathrm{dm}^{3}$, resulting in a $53 \%$ efficiency. Studies have shown that both tested powdered activated carbons have contributed to effective cleaning of aqueous solutions containing ibuprofen.
\end{abstract}

Keywords: ibuprofen, adsorption, powdery activated carbon

\section{INTRODUCTION}

At present, pharmaceuticals are one of the most dangerous anthropogenic contaminants. Wastewater from production plants, hospitals, private farms and landfills are the sources of their escape into the waters. Animal breeding also contributes to environmental pollution with pharmaceuticals. Veterinary antibiotics and growth promoters along with fertilizer for field fertilization can contribute to drug penetration by surface runoff to water and soil and cause disruption of biological wastewater treatment processes. [Deziel 2014, Khetan et.al. 2007, Kummerer 2009 and Tomska A. 2016]. Concentration of pharmaceutical residues in hospital wastewater is higher than in municipal wastewater [Lach et al. 2012]. Currently, around 100 different active pharmaceutical ingredients are regularly detected. The data on the occurrence of pharmaceuticals in the envi- ronment appeared in Poland in 2001 on the basis of data on the consumption of medicines [Czech 2012]. In the aquatic environment, the most common pharmaceuticals are beta blockers, nonsteroidal anti-inflammatory drugs, antibiotics, lipid regulators, anti-epileptics and female sex hormones [Deziel 2014, Nicolaou et al. 2007]. Because of the criterion of sales of medicines, Poland is sixth in the European Union, whereas it was in second place in 2007-2008 in terms of dynamics of development. The over-the-counter pain relievers are the most commonly prescribed drug group, accounting for approximately $34 \%$ of the overall pharmaceutical market [Kruszelnicka 2012]. Short-term toxicological studies indicated different sensitivity of aquatic organisms to ibuprofen. It may inhibit the reproductive capacity of Daphnia magna in small quantities, while a dose of $0.4 \mathrm{~g} / \mathrm{m}^{3}$ inhibits the growth of water lily. It is difficult to determine the actual 
impact of ibuprofen on living aquatic organisms, as the doses used in the studies exceeded the environmental amounts. In the amount of $0.2 \mathrm{~g} / \mathrm{m}^{3}$ Ibuprofen can affect the production of estrogens by aquatic organisms. On the other hand, the amount of $0.1 \mathrm{~g} / \mathrm{m}^{3}$ delays the hatching of the Japanese yolk egg [Guzik et al. 2015].

High purification technologies such as oxidation processes, ozonation, chlorination, UV photolysis, membrane filtration and adsorption [Arya et al. 2016, Herberer 2004, Miralles-Cuevas et al. 2015, Tong et al. 2012] are used to obtain high efficiency removal of selected drugs from aqueous solutions. The adsorption process plays an important role in the selection of a suitable adsorbent and its physical and chemical properties. Activated carbon is the most widespread adsorbent that is used on a large scale. Its most important feature (thanks to activation) is the extended surface area, well developed porous structure and a high volume of pores. Therefore, they are characterized by a higher adsorption capacity than other natural adsorbents. On the basis of a substantial amount of research, a wide range of work has been published which have shown that adsorption on activated carbon and many other adsorbents in granular, fibrous or dusty form are the best and most effective method of purifying water from organic compounds [lima et al. 2014, Rodriguez et al. 2016].

The study attempted to determine the usefulness of two dusty active carbons (Norit SA SUPER and Carbopol MB5) to remove ibuprofen from aqueous solutions.

\section{MATERIALS AND METHODS}

The model was a water-based ibuprofen (C13H18O2). It was made on the basis of distilled water. The initial concentration of ibuprofen in water was $C 0=20 \mathrm{mg} / \mathrm{dm}^{3}$.

In laboratory studies, powder commercial activated carbon fractions as an adsorption material, produced from selected plant and steam activated materials were used:

- PWA Norit SA Super activated carbon from Cabot Norit Nederland B.V.

- PWA Carbopol MB 5 Donau Carbon US LLC activated carbon.

Adsorbent particle size was less than $0.1 \mathrm{~mm}$.

\section{Method of conducting research}

The adsorption process was carried out using adsorbent dried at $105^{\circ} \mathrm{C}$. The content of ibuprofen was determined by an indirect method of determining the organic carbon content using the GE Analytical Instruments TOC Sievers InnovOx laboratory analyzer. A standard curve for the range of ibuprofen concentrations used in the study was prepared. Each series contained extra flasks that were blank (with adsorbent without adsorbate).

The study was conducted under static (nonflow) conditions. They were carried out in a series depending on the dust dose of the adsorbent.

Laboratory tests were conducted in two stages:

- Stage I - research to determine the initial conditions of the adsorption process - the effect of $\mathrm{pH}$ and the process of kinetics

- Stage II - Determining the effect of the adsorbent dose on the adsorption efficiency and determination of Freundlich adsorption isotherms.

\section{Effect of $\mathrm{pH}$ on the adsorption process}

The tests were performed for $\mathrm{pH}: 2,3,4,5$, $6,7,8,9,10,11,12,13$. Adsorbents were treated with $250 \mathrm{ml}$ of adsorbent, shaken for 5 hours, and after sedimentation $(24 \mathrm{~h})$ the determination of ibuprofen in solution was carried out.

\section{Effect of contact time on the adsorption process under static conditions (adsorption kinetics)}

The effect of contact time on the adsorption process was also determined at an adsorbent dose of $50 \mathrm{mg} / \mathrm{dm}^{3}$. The initial concentration of ibuprofen in the test water was $\mathrm{C} 0=20 \mathrm{mg} / \mathrm{dm}^{3}, \mathrm{pH}=$ 7. The adsorption flasks were shaken sequentially by $0.5 ; 1.0 ; 1.5 ; 2.0 ; 2.5 ; 3.0 ; 3.5 ; 4.0 ; 4.5 ; 5.0$; $5.5 ; 6.0$ hours and left for 24 hours for sedimentation and an ibuprofen marking was carried out.

Adsorption (adsorption capacity) was determined by the dependence:

$$
q_{r}=\frac{V \times\left(C_{0}-C\right)}{m}(\mathrm{~g} / \mathrm{g})
$$

where: $V$ - volume of adsorption $\left(\mathrm{dm}^{3}\right)$ $C O$ and $C$ - initial and equilibrium concentrations of phenol $\left(\mathrm{g} / \mathrm{m}^{3}\right)$, $m$ - mass of adsorbent $(\mathrm{g})$ 


\section{Effect of adsorbent dose on adsorption efficiency}

The effect of the adsorbent dose on the phenol adsorption efficiency was done at $\mathrm{pH}=7$, contact time $5.0 \mathrm{~h}$, for PWA doses of $1-300 \mathrm{mg} / \mathrm{dm}^{3}$.

\section{Adsorption isotherms}

The separation of adsorbate between solution and adsorbent at equilibrium was described by Freundlich and Langmuir adsorption isotherms, which depict the relationship between the amount of adsorbed substance and the equilibrium concentration. In exponential form, Freundlich's equation has the form:

$$
y / m=K \cdot C^{1 / n}
$$

where: $y / m$ - adsorption capacity,

$K$-isotherms,

$n$ - constant isotherm

$C$ - equilibrium concentration.

The Langmuir equation is expressed as:

$$
y / m=\frac{a \cdot b \cdot C}{1+b \cdot C}
$$

where: $y$-mass of adsorbed adsorbate,

$m$ - unit mass of the adsorbent,

$a, b-$ constant Langmuir equations,

$C$ - final concentration of adsorbate in solution (equilibrium concentration).

Studies were carried out in $0.5 \mathrm{dm}^{3}$ adsorbents, for ibuprofen $\mathrm{C} 0=20 \mathrm{mg} / \mathrm{dm}^{3}$ and variable doses of the adsorbents tested. The content of adsorbate at equilibrium qr, after 5 hours of shak- ing and 24 hours of sedimentation for the tested coals, was calculated from formula (1).

Phenol adsorption isotherms on adsorbents tested were set at $20^{\circ} \mathrm{C}, \mathrm{pH} 7.0$.

\section{RESULTS AND DISCUSSION}

\section{Effect of $\mathrm{pH}$}

Figure 1 depicts the final concentrations of ibuprofen (adsorption efficiency) in different $\mathrm{pH}$ ranges. Adsorption slightly decreased for PWA Carbopol as the $\mathrm{pH}$ of the solution decreased (5 -2). The highest adsorption (73\%) was recorded at $\mathrm{pH} 6,9$ and 10. At higher $\mathrm{pH}$ ranges (11-13) the efficiency remained at the same level of $73.5 \%$. For neutral, the percentage removal of phenol was slightly lower than for basic and was $71.5 \%$. At low $\mathrm{pH}$, adsorption was only $4 \%$ lower than in neutral. With respect to PWA Norit, the effect of the $\mathrm{pH}$ of the solution was similar to that of Carbopol. Ibuprofen particles exhibited a much higher affinity for the adsorbent at $\mathrm{pH}$ greater than 7, with adsorption efficiency greater than for Carbopol and oscillating between 90 and $93 \%$. For the coals tested, the increase in adsorption efficiency at $\mathrm{pH}>6$ was not significant enough to make water adjustments to further tests and was carried out at $\mathrm{pH}=7$.

\section{Adsorption kinetics}

The kinetics of the adsorption process consists of several successive stages. The first is the transport of the adsorbed particle from the solu-

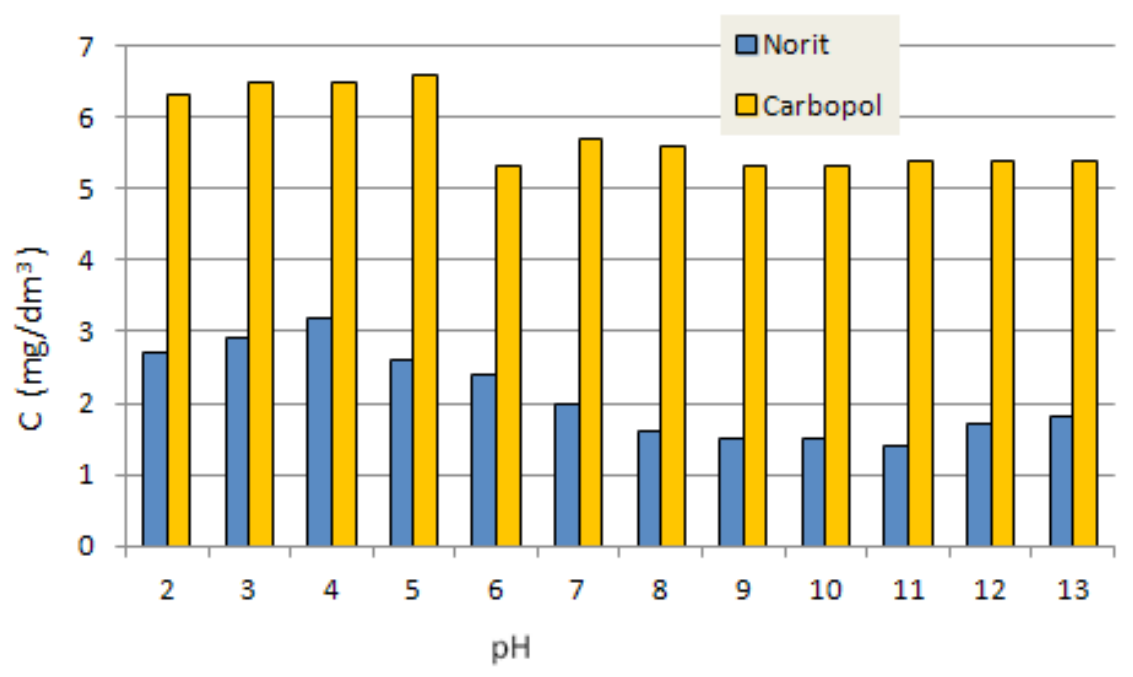

Figure 1. Effect of $\mathrm{pH}$ on the adsorption of ibuprofen 
tion volume phase to the adsorbent boundary layer, then the external diffusion (on the adsorbent surface), the internal diffusion - in the adsorbent structure and the last stage - the adsorbate reaction with the active site. Reaction in active sites occurs fastest, but adsorption kinetics limits the slowest processes. Under static (non-flowing) conditions, they are the diffusion phenomena at the interface and within the pores of the adsorbent. Transport to the volumetric phase is also of significance to which, in diluted solutions, the mixing or shaking time is affected. The concentration close to the adsorption equilibrium for PWA Norit was reached faster, after 4.5 hours, and the lowest achieved phenol concentrations (assumed as equilibrium) for Carbopol were obtained after $5 \mathrm{~h}$. The adsorption efficiency expressed as $\mathrm{S}=\mathrm{C} / \mathrm{C} 0$ (at $50 \mathrm{mg}$ / $\mathrm{Dm}^{3}$ ) for the assumed equilibrium concentration $\left(\mathrm{C}=2.0 \mathrm{mg} / \mathrm{dm}^{3}\right)$ for PWA Norit was higher and amounted to $\mathrm{S}=0.10$ and for Carbopol $\mathrm{S}=0.28$ $\left(\mathrm{C}=5.7 \mathrm{mg} / \mathrm{dm}^{3}\right)$ what is shown on Figure 2 .

In order to describe the kinetics of adsorption, two kinetic models are commonly used: the pseudo-first-order (PFO) model described by Lagergren's equation and the pseudo-second-order model (PSO) popularized by Ho et al [6]. The modeling process is about matching the empirical results with those equations and choosing the one which correlates the data better. Selecting a suitable model will not explain the mechanisms that control the rate of adsorption in the system, but may be helpful in determining the factors limiting the speed of the process [Płaziński et al.2011].
When analyzing data, the linear form of the equation is used more often. The PFO equation takes a form:

$$
\ln \left(q_{e}-q(t)\right)=\ln q_{e}-k_{1} t
$$

where: $t$ is the time,

$q$ the amount of adsorbate bound by the adsorbent (this amount may depend on time),

qe corresponds to $q$ at steady state, i.e. $q$ $(\mathrm{t} \rightarrow \infty)=q \mathrm{e}$;

$k 1$ is a constant, called PFO constant.

The kinetic curves for the adsorbents tested in the $f(t)=\log (q e-q(t))$ function are shown in Figure 3. On the basis of the least squares equations, $\mathrm{k} 1(1 / \mathrm{h})$ speed constants were calculated and adsorption at steady state and is provided in Table 1.

The linear pseudo II row (PSO) equation is as follows:

$$
\frac{t}{q(t)}=\frac{1}{k_{2} q_{Q}^{2}}+\frac{t}{q}
$$

where: $k 2$ is constant.

Graphs for PSO were prepared as a function of $\mathrm{f}(\mathrm{t})=\mathrm{t} / \mathrm{q}(\mathrm{t})$ and shown in Figure 4. Constants of $k_{2}(\mathrm{~g} / \mathrm{g} \cdot \mathrm{h})$ were calculated on the basis of slope and straight shifts. All calculated constant velocity $\mathrm{k} 2$ and adsorption capacity are provided in Table 1.

The adsorption kinetics for PWA Norit followed the PSO model, as evidenced by the high value of $\mathrm{R}^{2}(0.9642)$ and the approximate adsorption capacity ge. For the PFO model, the coefficient of determination $\mathrm{R}^{2}$ was also relatively

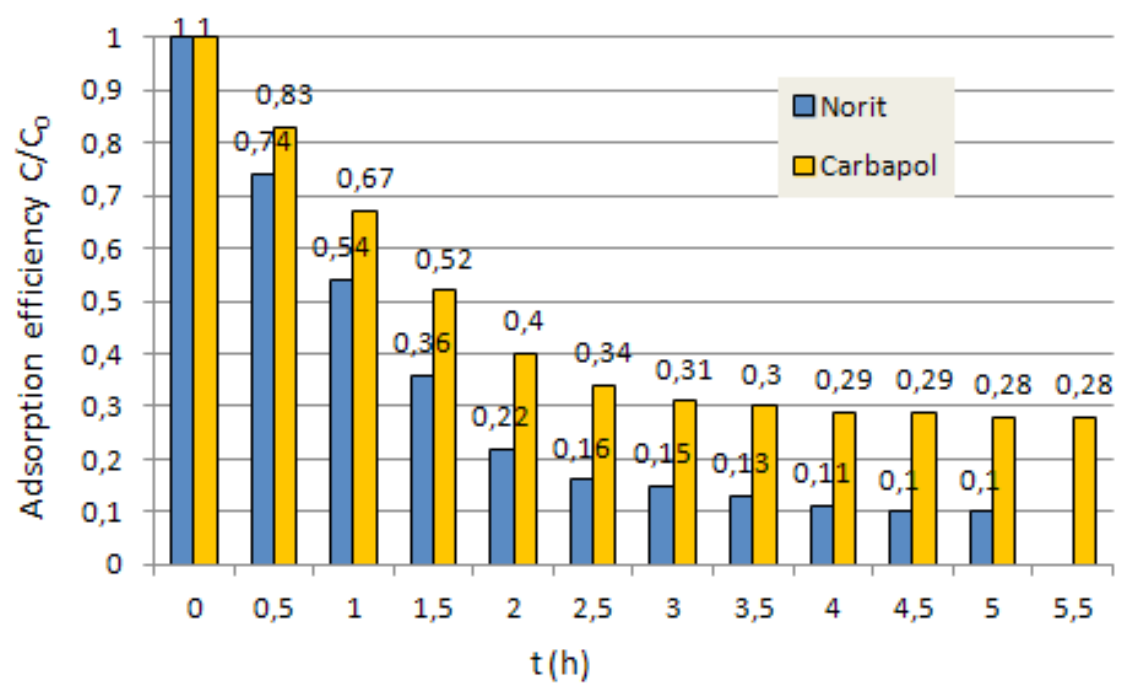

Figure 2. Influence of adsorption time on the effectiveness of the removal of ibuprofen 


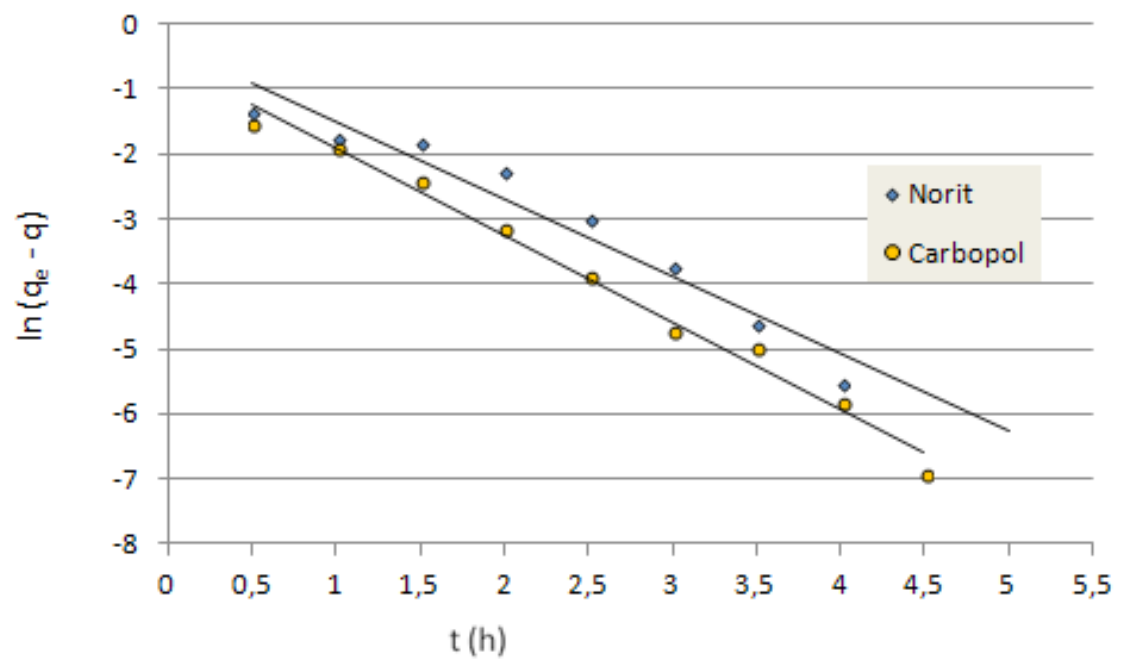

Figure 3. The course of adsorption kinetics of ibuprofenum described pseudo first-order equation

Table 1. Pseudo first- and pseudo second-order rate constants for adsorption of ibuprofen on activated carbons

\begin{tabular}{|c|c|c|c|c|c|c|c|}
\hline \multirow{2}{*}{ Adsorbent } & \multirow{2}{*}{$\mathrm{q}_{\mathrm{r}}(\mathrm{g} / \mathrm{g})$ - experimental } & \multicolumn{3}{|c|}{ Pseudo-first-order (PFO) } & \multicolumn{3}{|c|}{ Pseudo-second-order (PSO) } \\
\cline { 3 - 8 } & value & $\mathrm{k}_{1}\left(\mathrm{~h}^{-1}\right)$ & $\mathrm{q}_{\mathrm{e}}(\mathrm{g} / \mathrm{g})$ & $\mathrm{R}^{2}$ & $\mathrm{k}_{2}(\mathrm{~g} / \mathrm{g} \cdot \mathrm{h})$ & $\mathrm{q}_{\mathrm{e}}(\mathrm{g} / \mathrm{g})$ & $\mathrm{R}^{2}$ \\
\hline Norit & 0.448 & 1.1902 & 0.7234 & 0.9450 & 1.4579 & 0.4850 & 0.9642 \\
\hline Carbopol & 0.353 & 1.3337 & 0.5622 & 0.9868 & 1.2746 & 0.4167 & 0.9449 \\
\hline
\end{tabular}

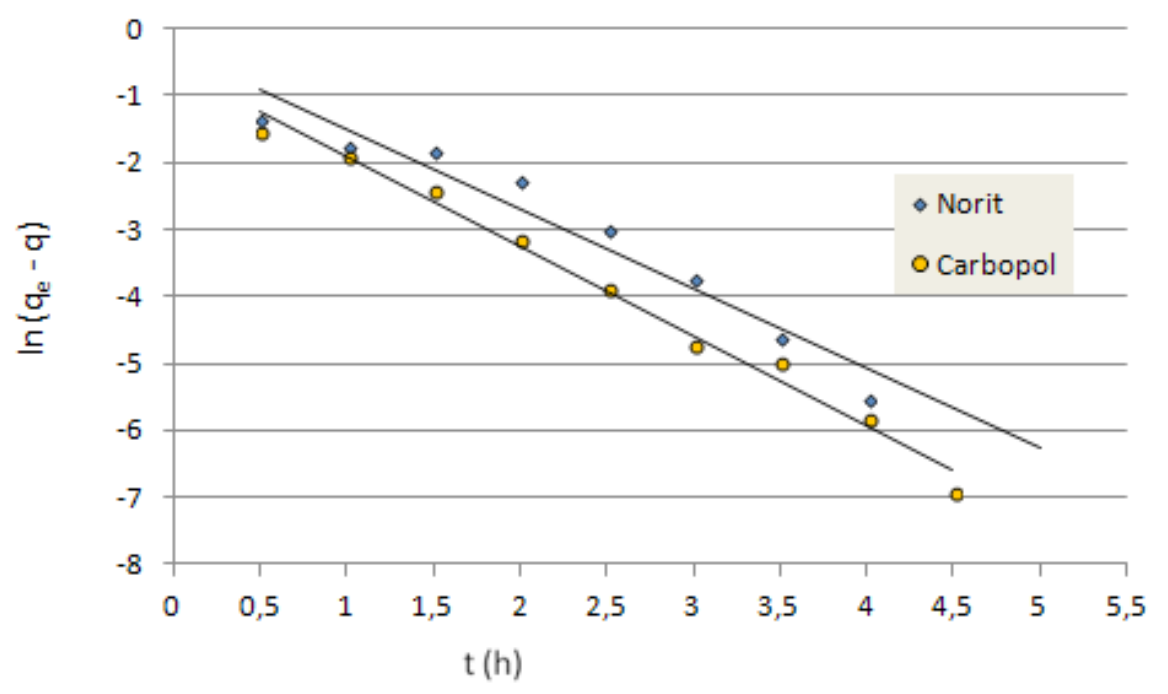

Figure 4. Adsorption kinetics of ibuprofen described pseudo second-order equation

high (0.945), but the experimental adsorption capacity (at steady state) was much lower than the theoretical one.

With regard to Carbopol, fitting the PFO model to the experimental values was the best. The determination coefficient was high and amounted to 0.987 , although differences in the adsorption capacities between those calculated and obtained in the tests were noted. The fastest adsorption was for PWA Norit as evidenced by a $\mathrm{k}_{2}$ constant of $1.45791 / \mathrm{h}$.
From the presented relationships, the efficiency of adsorption increased with the time of water contact with the adsorbent, but its speed (highest in the first 60 minutes) decreased sharply after 4 hours. The adsorption process was much slower and its continuation did not significantly affect the removal efficiency of phenol. In further studies (adsorption isotherms and dose effects), due to slight changes in the adsorption kinetics, the mixing time for all adsorbents was assumed to be 5 hours. 


\section{ADSORPTION ISOTHERMS}

Freundlich ibuprofen (exponential) and Lanqmuira (linear) adsorption isotherms (in linear form) for the adsorbents studied are shown in Figures 5 and 6.

The determined values, together with the determination coefficients $\mathrm{R}^{2}$, are given in Table 2 . The isotherms (determined in static conditions) indicate that the maximum adsorption capacity for PWA Norit was $\mathrm{qr}=0.4480 \mathrm{~g} / \mathrm{g}$ and was greater than for Carbopol $\mathrm{qr}=0.3533 \mathrm{~g} / \mathrm{g}$. The $\mathrm{K}$ values, which express the maximum adsorption on the surface of the adsorbent, are respectively 0.2447 for Norit, and only 0.1464 for Carbopol.
The $\mathrm{n}$ factor for the adsorbents tested is greater than 1, which may indicate that the surface concentration of the adsorbate rises more slowly than its concentration in solution and substantially no full saturation is achieved as highadsorption sites are always present on the surface. The highest value of determination coefficient for Norit $\left(R^{2}=0.9432\right)$ was determined for the Langmuir isotherm, which demonstrates the good fit of this theoretical model to the experimental value and may indicate an advantage of monomolar adsorption on the active centres. For PWA Carbopol, the adsorption behavior is better described by the Freundlich isotherm $\left(\mathrm{R}^{2}=0.9535\right)$, so that the adsorbant adsorbate can be a coated multilayer.

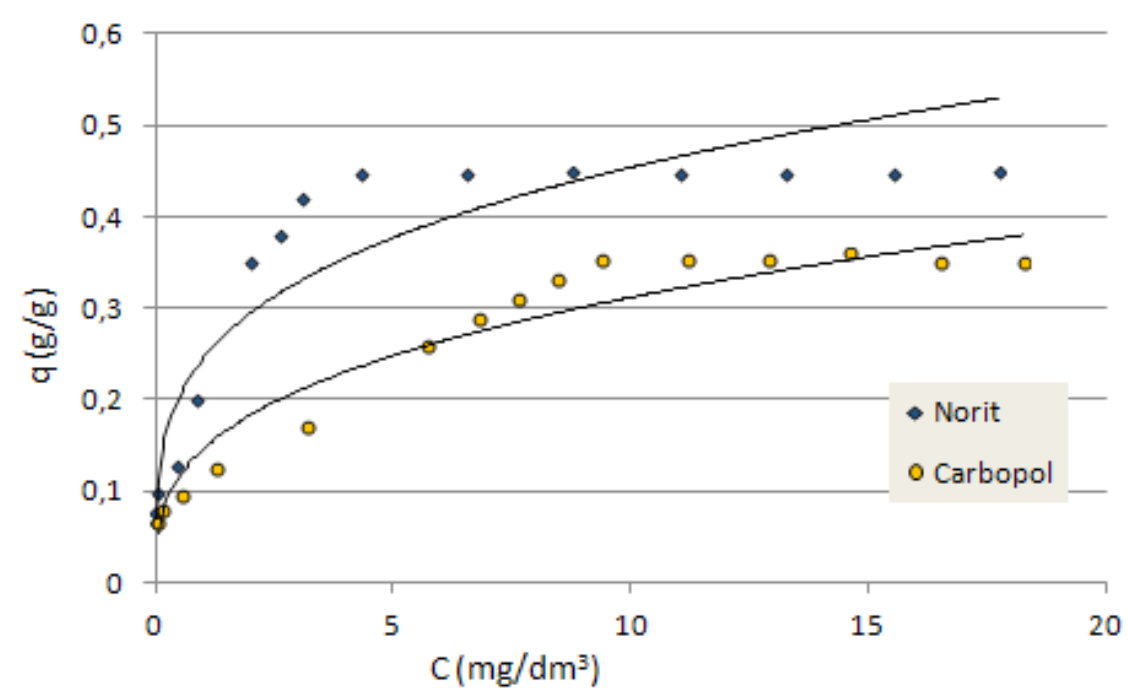

Figure 5. Adsorption isotherms of Freundlich ibuprofenum

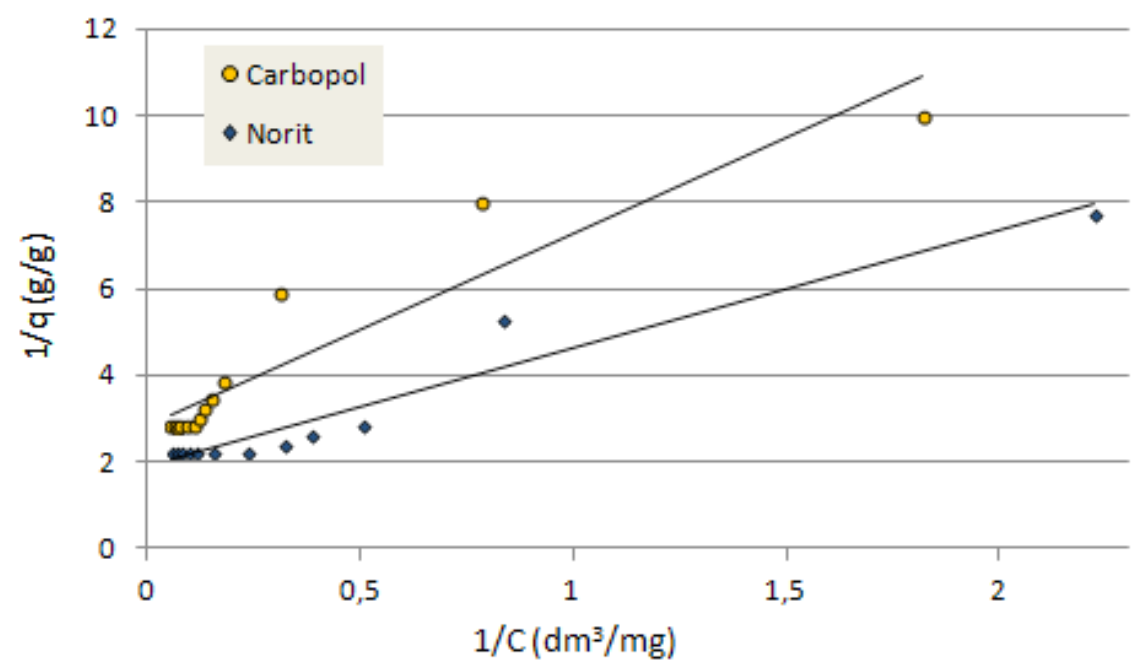

Figure 6. Adsorption isotherms Langmuir of ibuprofenum 
Table 2. Values of factors $\mathrm{n}$ and $\mathrm{K}$ of Freudlich and Langmuir isotherms

\begin{tabular}{|c|c|c|c|c|c|c|}
\hline \multirow{2}{*}{ Adsorbent } & \multicolumn{3}{|c|}{ Factors of Freudlich } & \multicolumn{3}{c|}{ Factors of Lanqumir } \\
\cline { 2 - 7 } & $\mathrm{n}$ & $\mathrm{K}$ & $\mathrm{R}^{2}$ & $\mathrm{a}$ & $\mathrm{b}$ & $\mathrm{R}^{2}$ \\
\hline Norit & 3.73 & 0.2447 & 0.9373 & 0.526 & 0.698 & 0.9432 \\
\hline Carbopol & 3.05 & 0.1464 & 0.9535 & 0.350 & 0.645 & 0.8850 \\
\hline
\end{tabular}

\section{EFFECT OF DOSE ON ADSORPTION}

The effectiveness of adsorption also depended on the amount of adsorbent used. This dose, with comparable efficacy, was variable depending on the type of adsorbent. Figure 7 illustrates the effect of selected adsorbent doses on the final concentration of ibuprofen in aqueous solution.
It is evident that a higher dose of adsorbent gave a better end result of the process. For PWA Norit at $200 \mathrm{mg} / \mathrm{dm}^{3}, 99.8 \%$ efficacy was achieved, and for PWA Carbopol, such efficacy gave a much higher dose of $300 \mathrm{mg} / \mathrm{dm}^{3}$. The achievable adsorption capacity $\mathrm{P}$ (for selected doses (Figure 8 ) was inversely proportional to the adsorption efficiency.

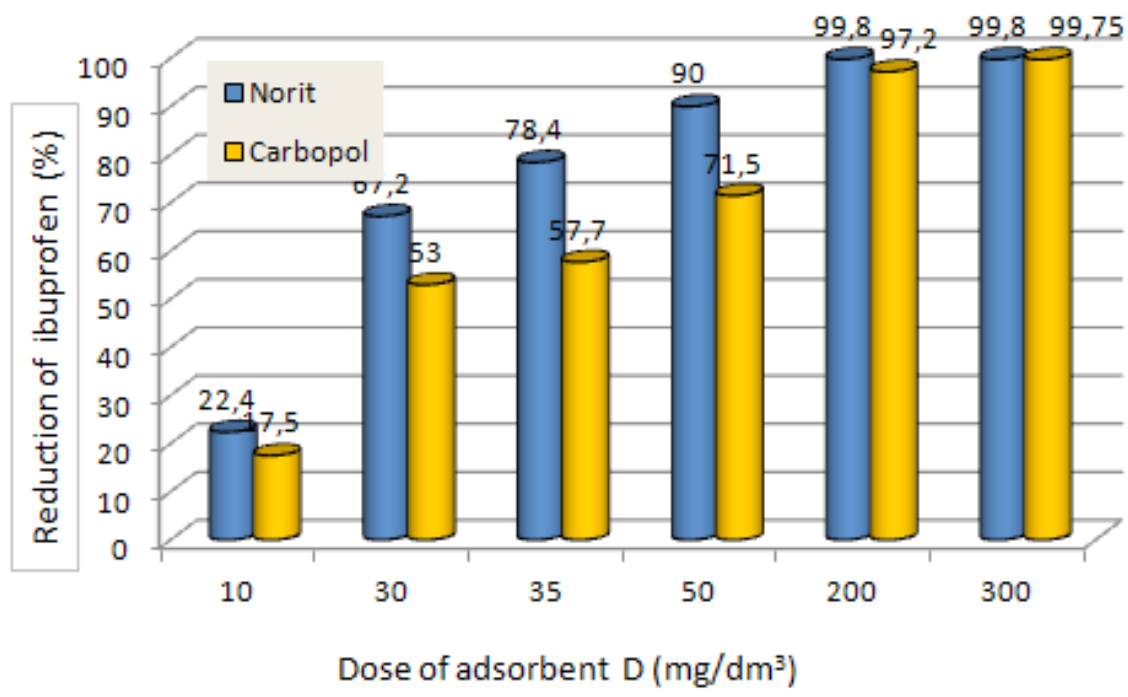

Fig. 7. Effect of dose on the adsorption efficiency

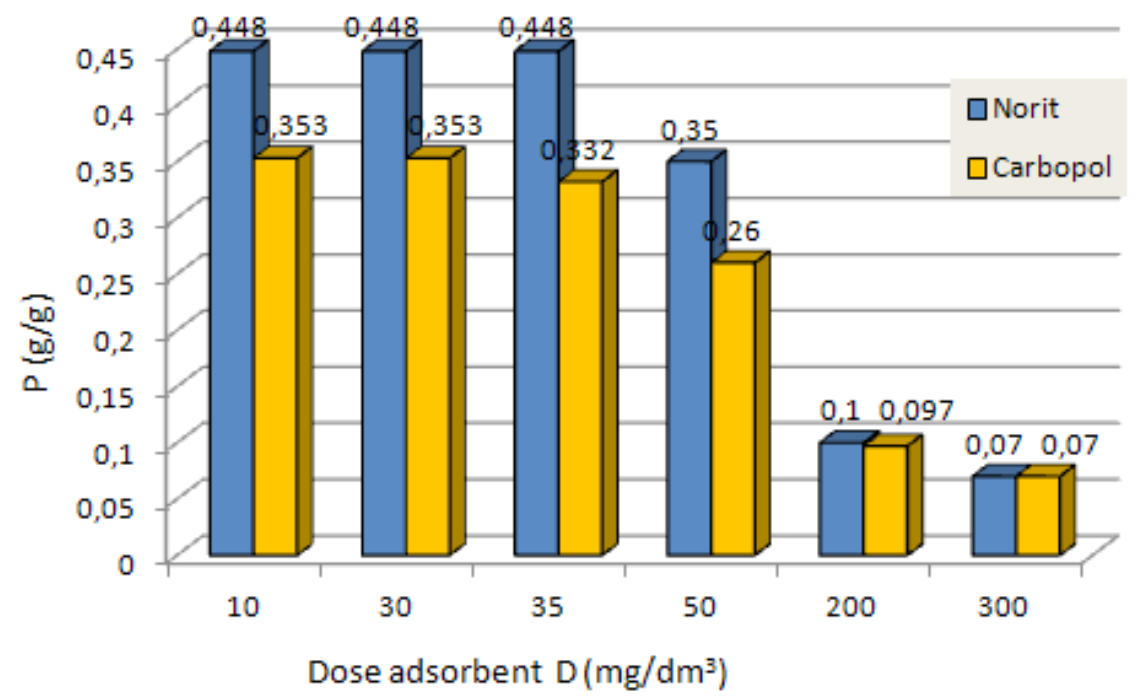

Figure 8. Effect of dose on the adsorption capacity $\mathrm{P}$ 
For PWA Norit it ranged from 0.07 to 0.448 $\mathrm{g} / \mathrm{g}$, and for PWA Carbopol from 0.07 to 0.353 $\mathrm{g} / \mathrm{g}$. At the maximum (experimental) adsorption capacity, the adsorption efficiency was $78.4 \%$ for dose $\mathrm{D}=35 \mathrm{mg} / \mathrm{dm}^{3}$. With regard to Carbopol, the highest efficiency (53\%), with maximum capacity, gave a dose of $\mathrm{D}=35 \mathrm{mg} / \mathrm{dm}^{3}$. The observed differences in the efficacy of ibuprofen removal between individual adsorbent doses indicate a better utilization of the porous structure of PWA Norit.

\section{CONCLUSIONS}

- The solution's reaction did not have a significant impact on the adsorption capacity of the adsorbents tested. The ibuprofen compounds for both active carbons showed a higher affinity for the adsorbent at a $\mathrm{pH}$ above 7 , with adsorption efficiencies greater for PWA Norit SA Super.

- The adsorption rate varied as a function of the adsorbate adsorbent contact time (s) and dropped sharply after 4 hours. Kinetics of adsorption of ibuprofen for PWA Norit SA Super is well described in the PSO model (Pseudosecond-order), as evidenced by the high value of the determinant $\mathrm{R}^{2}=0.9642$ and similar to the experimental adsorption capacity ge. With respect to Carbopol MB5, the Pseudo-first-order PFO with a determinant of $\mathrm{R}^{2}=0.9868$ was a better fit to experimental values.

- Adsorption of ibuprofen for PWA Norit SA Super is well described by Langmuir isotherms. The value of the determination coefficient was $\mathrm{R}^{2}=0.9432$. For PWA Carbopol, the course of adsorption followed the Freundlich adsorption model $\left(\mathrm{R}^{2}=0.9535\right)$.

- Dose of adsorbents influenced both the process efficiency and the adsorption capacity achieved. For PWA Norit $99.8 \%$ efficacy was obtained at a dose of $200 \mathrm{mg} / \mathrm{dm}^{3}$, and for PWA Carbopol such efficacy was $300 \mathrm{mg} / \mathrm{dm}^{3}$. The maximum adsorption capacity for PWA Norit was $\mathrm{q}=0.448 \mathrm{~g} / \mathrm{g}$, for a dose of $35 \mathrm{mg} /$ $\mathrm{dm}^{3}$, at $78.7 \%$ efficacy. With respect to Carbopol, the highest adsorption capacity $(\mathrm{q}=0.353$

$\mathrm{g} / \mathrm{g}$ ) was achieved at a dose of $30 \mathrm{mg} / \mathrm{dm}^{3}$, resulting in 53\% efficiency. The observed differences in ibuprofen removal indicate a better utilization of the porous structure of PWA Norit SA Super.
- Studies have shown that polyclonal active carbon fractions could be used to effectively clean solutions containing ibuprofen. The advantage of PWA is that it can be used at a water treatment plant in emergency situations, which makes it possible to use it in water treatment systems.

\section{REFERENCES}

1. Arya V., Philip L. 2016. Removal of Pharmaceuticals from Water Using Adsorption, Trends in Asian Water Environmental Science and Technology , Chapter 9, 105-114.

2. Czech B. 2012. Removal of pharmaceuticals from water and wastewater using adsorption and photocatalytic methods, Science for the Economy, 2, 443-452.

3. Deziel N.2014. Pharmaceuticals in Wastewater Treatment Plant Effluent Waters, Scholarly Horizons: University of Minnesota, Morris Undergraduate Journal, 2(4), 1-20.

4. Guzik U. Marchlewicz A., Wojcieszyńska D. 2015. Properties, occurrence and biodegradation of ibuprofen in aquatic environment, Environmental Protection (1), $65-70$.

5. Heberer T. , Feldmann D. 2004. Removal of Pharmaceutical Residues from Contaminated Raw Water Sources by Membrane Filtration, Pharmaceuticals in the Environment, 391-410.

6. Ho Y.S., McKay G.1990. Pseudo-second-order model for sorption processes, Process Biochemistry, 34, 451-465.

7. Khetan S. K., Collins T. J. 2007.Human pharmaceuticals in the aquatic environment: a challenge to green chemisty," Chemical Reviews, 107 (6), 2319-2364.

8. Kruszelnicka I., Ginter-Kramarczyk D., Zając A., Zembrzuska J. 2012. The problem of the presence of pharmaceuticals in sewage, Water Supply and Sewerage (5), 96-99.

9. Kümmerer K. 2009. The presence of pharmaceuticals in the environment due to human use-present knowledge and future challenges," Journal of Environmental Management, 90(8), 2354-2366.

10. Lach J., Szymonik A. 2012. Hazards of the aquatic environment by the presence of pharmaceuticals, Engineering and Environmental Protection, 3, 249-263.

11. Lima D. R. S., Baêta B. E. L., Aquino S. F. 2014. Removal of Pharmaceuticals and Endocrine Disruptor Compounds from Natural Waters by Clarification Associated with Powdered Activated Carbon, Water, Air, \& Soil Pollution, 225:2170. 
12. Miralles-Cuevas S., Oller I., Sanchez Perez J.A., Malato S. 2015. Application of solar photo-Fenton at circumneutral $\mathrm{pH}$ to nanofiltration concentrates for removal of pharmaceuticals in MWTP effluents, Environmental Science and Pollution Research, 22(2), 846-855.

13. Nikolaou A., Meric S., Fatta D. 2007. Occurrence patterns of pharmaceuticals in water and wastewater environments," Analytical and Bioanalytical Chemistry, 387(4), 1225-1234.

14. Płaziński W., Rudziński W. 2011. Adsorption kinetics on the border of phases solution/solid. Mean- ing of pseudo-first order and pseudo-second order equations, Chemical News 65 (11-12), 1055-1067.

15. Rodriguez E. 2016. Campinas M., Acero J. L., Investigating PPCP Removal from Wastewater by Powdered Activated Carbon/Ultrafiltration Water, Air, \& Soil Pollution 227:177.

16. Tomska A. 2016. Influence of selected pharmaceuticals on activated sludge dehydrogenase activity, Ecological Engineering; 48, 214-218.

17. Tong A. Y. C. , Braund R. 2012. TiO2-assisted photodegradation of pharmaceuticals - a review, Open Chemistry,10/4, 989-1027. 